\title{
Comparison of Two-point Discrimination Perception in Stroke Patients with and without Diabetes Mellitus
}

\author{
Jin-Seop Kim, PT, $\mathrm{PhD}^{1 *}$, Seung-Ju YI, PT, $\mathrm{PhD}^{1)}$ \\ 1) Department of Physical Therapy, Andong Science College: 496 Gyo-ri, Seohu-myeon, Andong-si, \\ Gyeongsangbuk-do 760-822, Republic of Korea. TEL: +82 54-851-3727, FAX: +82 54-851-3559
}

\begin{abstract}
Purpose] The aim of this study was to compare two-point discrimination (TPD) perception in stroke patients with diabetes mellitus (DM) and without diabetes mellitus (non-DM). [Subjects] The subjects were 53 poststroke hemiparetic patients (21 stroke patients with DM; 32 stroke patients without DM). [Methods] TPD was measured on the tips of the first through fifth fingers on both the affected and unaffected sides. [Result] Comparison of TPD between fingers on the unaffected side and affected side fingers showed significantly poorer responses in all five fingers on the affected side. TPD was also significantly poorer in the DM group compared with the non-DM group in all five fingers on the affected side, but no differences were observed for the unaffected side. [Conclusion] These findings suggest that TPD was significantly poorer in the fingers on the affected side vs. the unaffected side in poststroke hemiparetic patients. DM caused a significantly poorer TPD in the fingers on the affected side in poststroke patients but had no significant effect on the fingers on the unaffected side.

Key words: Stroke, Two-point discrimination, Diabetes mellitus
\end{abstract}

(This article was submitted Mar. 1, 2013, and was accepted Apr. 8, 2013)

\section{INTRODUCTION}

The prevalence of diabetes mellitus (DM) in Korea is estimated to be $7.3 \%$, and this has increased about 5 -fold over the past 30 years according to a report of the Korea National Health and Nutrition Examination Surveys ${ }^{1)}$. DM represents a strong independent risk factor for stroke ${ }^{2)}$, as long-term diabetes results in a variety of subtle cerebral disorders that occur more frequently than is common ${ }^{3}$. DM also affects conductive function in the central and peripheral somatosensory pathways ${ }^{4}$.

The incidence of sensory deficit in stroke is high ${ }^{5)}$. Severe sensory loss after stroke can cause patients to avoid use of their affected fingers in manual activities, even though good voluntary muscle activity is present $\left.{ }^{6}\right)$. Sensory functions are important for a patient's rehabilitation to restore impaired motor function. Therefore, Dellon ${ }^{7}$ suggested use of an instrument to measure the sensory threshold of twopoint discrimination (TPD).

TPD is defined as the smallest separation between two stimulations placed on the skin that can be discriminated as two separate points. TPD testing has been found to be particularly helpful in the assessment of injuries to nerves distributed to the hand sensor ${ }^{7)}$. TPD has been demonstrated to be a valid measurement of functional sensibility in the hand with good test ${ }^{8)}$. Previous studies have used this measurement to assess sensory capacity in adult men and women $^{9)}$, traumatic brain injury patients ${ }^{10)}$, lumbosacral

${ }^{*}$ To whom correspondence should be addressed.

E-mail: skylove3373@hanmail.net radiculopathy patients ${ }^{11)}$ and normal subjects ${ }^{12)}$. However, most TPD studies have been conducted on peripheral injury patients or normal subjects, and few have focused on central nervous system disorders. To our knowledge, studies on poststroke patients are lacking, and the influence of DM on TPD has yet to be studied.

Therefore, this study was designed to identify the extent of differences in TPD in fingers on the affected and unaffected sides in poststroke hemiparetic patients. A second aim was to estimate the influence of DM on finger sensory abilities following stroke.

\section{SUBJECTS AND METHODS}

Fifty-three poststroke patients were recruited as subjects from the stroke rehabilitation center of An-dong Hospital (Table 1). Patients were excluded if they had previous neurological injury or disease (for example, traumatic brain injury, peripheral neuropathy, and brachial plexus injury), language deficits or psychiatric history. Informed consent was obtained from each subject prior to inclusion in the study.

TPD was measured following the guidelines published by Moberg in $1990^{8}$. Accuracy was increased by using Aesthesiometers (Sammons Preston, USA) with a precision of $1 \mathrm{~mm}$ in place of a paperclip. During testing, the examiner and the examinee were seated with their fingers stabilized against a firm support to avoid movement. A screen was used to prevent the subjects from visualizing their fingers. TPD sensitivity in each region was examined by lightly touching the subject's skin at either one point or 
1008 J. Phys. Ther. Sci. Vol. 25, No. 8, 2013

Table 1. General characteristics of the subjects $(n=53)$

\begin{tabular}{lcccccc}
\hline & Age (years) & Height $(\mathrm{cm})$ & Weight $(\mathrm{Kg})$ & Sex $(\mathrm{F} / \mathrm{M})$ & $\begin{array}{c}\text { Duration } \\
\text { months }\end{array}$ & $\begin{array}{c}\text { Diabetes } \\
\text { Mellitus } \\
(\mathrm{Y} / \mathrm{N})\end{array}$ \\
\hline Subjects & $63.25 \pm 9.17^{\mathrm{a}}$ & $160.58 \pm 6.94$ & $59.79 \pm 10.83$ & $23 / 30$ & $2.01 \pm 2.25$ & $21 / 32$ \\
\hline
\end{tabular}

${ }^{\mathrm{a}}$ Mean $\pm \mathrm{SD}$

Table 2. Comparison of the fingers on the affected side and unaffected side in stroke patients $(\mathrm{n}=53)$

\begin{tabular}{lcc}
\hline Variable & $\begin{array}{c}\text { Unaffected } \\
\text { side }(\mathrm{mm})\end{array}$ & $\begin{array}{c}\text { Affected side } \\
(\mathrm{mm})\end{array}$ \\
\hline First finger* & $4.72 \pm 1.06$ & $6.32 \pm 2.99$ \\
Second finger* & $4.92 \pm 1.28$ & $6.74 \pm 3.23$ \\
Third finger* & $5.66 \pm 1.59$ & $7.62 \pm 3.81$ \\
Fourth finger* & $6.23 \pm 1.81$ & $8.57 \pm 4.20$ \\
Fifth finger* & $7.08 \pm 2.00$ & $9.36 \pm 4.36$ \\
\hline
\end{tabular}

Mean $\pm \mathrm{SD},{ }^{*} \mathrm{p}<0.05$

two points simultaneously. This type of sensory testing is appropriately conducted using pressure that depresses the skin no more than $1 \mathrm{~mm}$. Testing commenced with $0 \mathrm{~mm}$ between the two points of the Aesthesiometers, and then the distance was gradually increased until the subject was able to perceive two points. Testing was then repeated on the next finger. The collected data were analyzed with SPSS ver. 12.0. All parameters for all subjects were tested by the Kolmogorov-Smirnov test to show that the data were normally distributed. An independent t-test was performed to test differences between the affected and unaffected sides and between DM and non-DM patients. The significance level was set at $\mathrm{p}<0.05$.

\section{RESULTS}

Comparison of TPD between fingers on the unaffected and affected side fingers showed significantly poorer capabilities in all five fingers on the affected side $(p<0.05)$. Comparison of TPD between the DM and non-DM groups showed a significantly poorer response in all fingers on the affected side in the DM group $(\mathrm{p}<0.05)$ However, no significant differences were noted between the DM and non-DM groups for any of the fingers on the unaffected side $(\mathrm{p}>0.05)$ (Table 2).

\section{DISCUSSION}

The results of the study showed that the TPD of the stroke patients was significantly poorer on the affected than on the unaffected side. The stroke patients had suffered a cerebral vascular accident on the right or left brain hemisphere. Sensory processing involves many somatosensory pathways and many areas of the brain. Therefore, sensory impairment can result from a lesion located anywhere from the brainstem to the cortex ${ }^{13)}$.
Table 3. Comparison of TPD in stroke patients with and without diabetes mellitus $(n=53)$

\begin{tabular}{llcc}
\hline Finger & & $\begin{array}{c}\text { DM group } \\
(\mathrm{n}=21)\end{array}$ & $\begin{array}{c}\text { Non-DM group } \\
(\mathrm{n}=32)\end{array}$ \\
\hline \multirow{2}{*}{ First } & Unaffected & $4.90 \pm 1.04^{\mathrm{a}}$ & $4.59 \pm 1.07^{\mathrm{b}}$ \\
& Affected* & $7.76 \pm 3.85$ & $5.38 \pm 1.77$ \\
\multirow{2}{*}{ Second } & Unaffected & $5.17 \pm 1.24$ & $4.78 \pm 1.31$ \\
& Affected* & $8.48 \pm 3.93$ & $5.59 \pm 2.03$ \\
\multirow{2}{*}{ Third } & Unaffected & $5.90 \pm 1.48$ & $5.50 \pm 1.67$ \\
& Affected* & $9.38 \pm 4.97$ & $6.47 \pm 2.23$ \\
\multirow{3}{*}{ Fourth } & Unaffected & $6.52 \pm 1.66$ & $6.03 \pm 1.91$ \\
& Affected* & $10.62 \pm 5.63$ & $7.22 \pm 2.11$ \\
& Unaffected & $7.33 \pm 2.11$ & $6.91 \pm 1.94$ \\
& Affected* & $11.14 \pm 5.66$ & $8.19 \pm 2.76$ \\
\hline
\end{tabular}

${ }^{\mathrm{a}}$ Mean $\pm \mathrm{SD} ;{ }^{*} \mathrm{p}<0.05 ;{ }^{\mathrm{b}}$ millimeters $(\mathrm{mm})$

Kim and Choi ${ }^{14)}$ stated that discriminative sensory disturbances, which often occur bilaterally in some modalities, are common in patients with unilateral stroke, even in those with intact sensory function on routine examination. The study of Van Heest et al. ${ }^{15)}$ showed that $90 \%$ of children with spastic hemiplegic damage had a TPD deficit. Similarly, the present study showed significantly poorer TPD in the fingers on the affected side compared with those on the unaffected side in poststroke patients.

The present study investigated the influence of DM on finger sensory perception in poststroke hemiparetic patients. Louraki et al. ${ }^{13)}$ determined that DM can affect both the peripheral and autonomic nervous system. However, our results showed that DM had a significant negative influence on the fingers on the affected side in poststroke hemiparetic patients. Therefore, DM may influence the poststroke clinical evaluation, especially in the initial phase, while the area of the cerebral injury is increasing ${ }^{16)}$. Alterations in cerebral blood supply and metabolic derangements probably play a role, as they do in the pathogenesis of $\mathrm{DM}^{3)}$. Therefore, the DM group was more damaged in both primary somatosensory and ipsilateral supplementary perception when compared with the non-DM group.

In conclusion, our results suggest that TPD is significantly poorer in the fingers on the affected side than in those on the unaffected side in poststroke hemiparesis. Effects of DM were also apparent as poorer TPD in the fingers on the affected side in poststroke patients, although no differences were observed for TPD in the fingers on the unaffected side (Table 3).

The study had a number of limitations, particularly due to the relatively small sample size and the predominantly 
cross-sectional methodology used for it. Future research would benefit from a larger sample size and a longitudinal design.

\section{REFERENCES}

1) Kim DJ: The epidemiology of diabetes in Korea. Diabetes Metab J, 2011, 35: 303-308. [Medline] [CrossRef]

2) Goldstein LB, Adams R, Becker K, et al.: Primary prevention of ischemic stroke: a statement for healthcare professional from the Stroke Council of the American Heart Association. Stroke, 2001, 32: 280-299. [Medline] [CrossRef]

3) Biessels GJ, Kappelle AC, Bravenboer B, et al.: Cerebral function in diabetes mellitus. Diabetologia, 1994, 37: 643-650. [Medline] [CrossRef]

4) Suzuki C, Ozaki I, Tanosaki M, et al.: Peripheral and central conduction abnormalities in diabetes mellitus. Neurology, 2000, 54: 1932-1937. [Medline] [CrossRef]

5) Carey LM: Somatosensory loss after stroke. Crit Rev Phys Rehabil Med, 1995, 7: 51-91.

6) Broeks JG, Lankhorst GJ, Rumping K, et al.: The long-term outcome of arm function after stroke: results of a follow-up study. Disabil Rehabil 1999, 21: 357-364. [Medline] [CrossRef]

7) Dellon AL, Curtis RM, Edgerton MT: Re-education of sensation in the hand after nerve injury and repair. Plast Reconstr Surg, 1974, 53: 297-305.
[Medline] [CrossRef]

8) Moberg E: Two-point discrimination test. A valuable part of hand surgica rehabilitation, e.g. in tetraplegia. Scand J Rehabil Med, 1990, 22: 127-134. [Medline]

9) Nolan MF: Two-point discrimination assessment in the upper limb in young adult men and women. Phys Ther, 1982, 62: 965-969. [Medline]

10) Heriseanu R, Baguley IJ, Slewa-Younan S: Two-point discrimination following traumatic brain injury. J Clin Neurosci, 2005, 12: 156-160. [Medline] [CrossRef]

11) Saeidian SR, Moghaddam HF, Ahangarpour A, et al.: Two-Point Discrimination Test in the Treatment of Right-handed Females with Lumbosacral Radiculopathy. Iran J Med Sci, 2011, 36: 296-299. [Medline]

12) Tamura $Y$, Hoshiyama $M$, Inui $K$, et al.: Central mechanisms for two-point discrimination in humans. Neurosci Lett, 2003, 342: 187-190. [Medline] [CrossRef]

13) Yekutiel M, Guttman E: A controlled trial of the retraining of the sensory function of the hand in stroke patients. J Neurol Neurosurg Psychiatry, 1993, 56: 241-244. [Medline] [CrossRef]

14) Kim JS, Choi KS: Discriminative sensory dysfunction after unilateral stroke. Stroke, 1996, 27: 677-682. [Medline] [CrossRef]

15) Van Heest AE, House J, Putnam M: Sensibility deficiencies in the hands of children with spastic hemiplegia. J Hand Surg Am, 1993, 18: 278-281. [Medline] [CrossRef]

16) Siemkowicz E, Gjedde A: Post-ischemic coma in rat: effect of different pre-ischemic blood glucose levels on cerebral metabolic recovery after ischemia. Acta Physiol Scand, 1980, 110: 225-232. [Medline] [CrossRef] 